\title{
Correction to: Impact of multiple drying-wetting cycles on shear behaviour of an unsaturated compacted clay
}

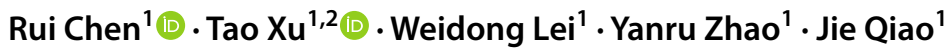

Published online: 9 February 2019

๑) Springer-Verlag GmbH Germany, part of Springer Nature 2019

\section{Correction to: Environmental Earth Sciences (2018) 77:683 https://doi.org/10.1007/s12665-018-7868-6}

In the original publication, Fig. 5c in (ii) Series 2 and Fig. 6c in

(ii) Series 2 are incorrect. The correct figure is the one below:

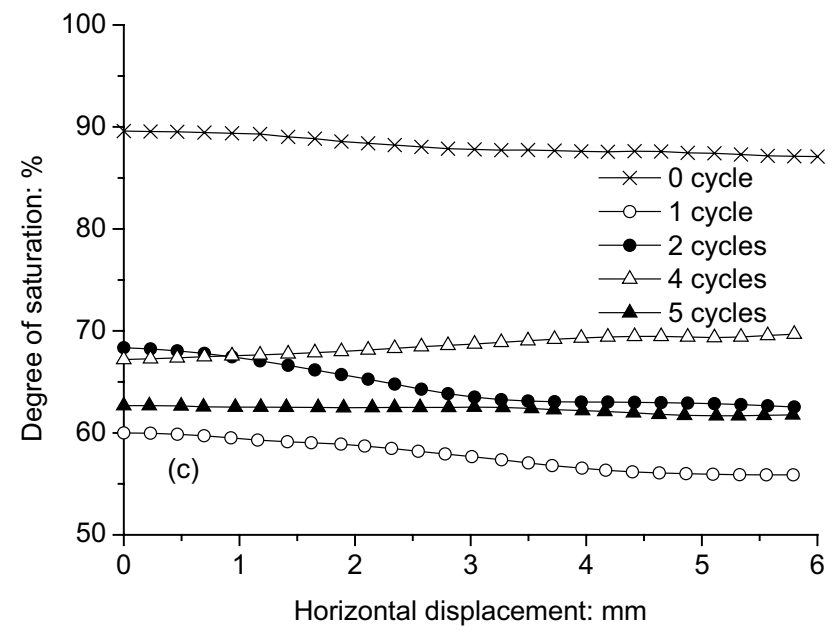

(ii) Series 2

Fig. 5 Shear behaviour after different numbers of dryingwetting cycles at $\left(\sigma_{v}-u_{a}\right)=50 \mathrm{kPa}$ a a shear stress, b vertical displacement and $\mathbf{c}$ degree of saturation, versus horizontal displacement

The original article can be found online at https://doi.org/10.1007/ s12665-018-7868-6.

Tao Xu

tao.xu@ugent.be

1 Department of Civil and Environmental Engineering, Harbin Institute of Technology (Shenzhen), Shenzhen University

Town, Xili, Shenzhen 518055, China

2 Laboratory of Geotechnics, Ghent University,

Technologiepark 905, Ghent 9052, Belgium

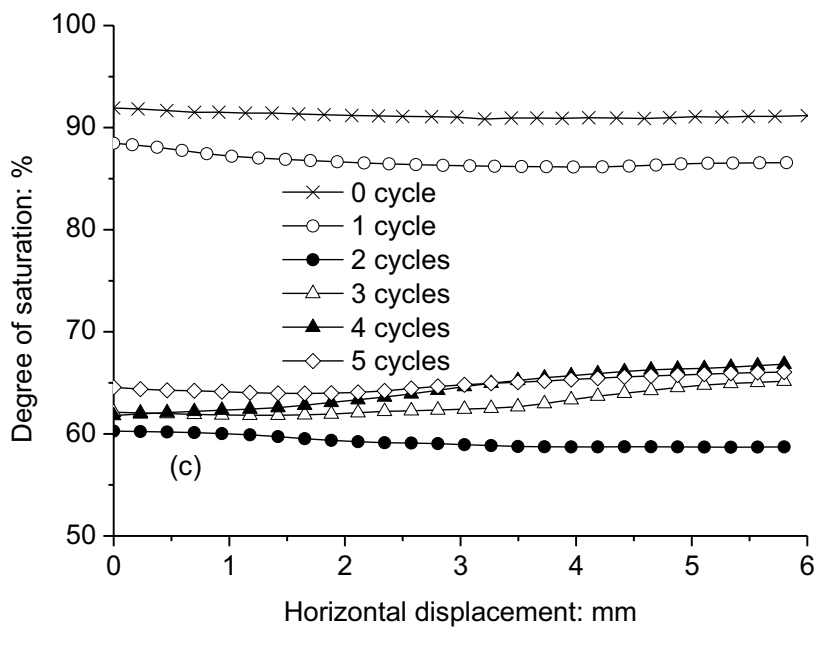

Fig. 6 Shear behaviour after different numbers of dryingwetting cycles at $\left(\sigma_{v}-u_{a}\right)=200 \mathrm{kPa}$ : a shear stress, b vertical displacement and $\mathbf{c}$ degree of saturation, versus horizontal displacement

Publisher's Note Springer Nature remains neutral with regard to jurisdictional claims in published maps and institutional affiliations. 